Original Article

\title{
The role of calmodulin in regulating calcium-permeable PKD2L1 channel activity
}

\author{
Eunice Yon June Park\#, Julia Young Baik\#, Misun Kwak, and Insuk So* \\ Department of Physiology, Seoul National University College of Medicine, Seoul 03080, Korea
}

\author{
ARTICLE INFO \\ Received January 22, 2019 \\ Revised March 26, 2019 \\ Accepted March 26, 2019 \\ *Correspondence \\ Insuk So \\ E-mail: insuk@snu.ac.kr
}

\section{Key Words}

Calcium

Calmodulin

Ion channel

Polycystic kidney

Transient receptor potential channels

\#These authors contributed equally to this work.
ABSTRACT Polycystic kidney disease 2-like-1 (PKD2L1), polycystin-L or transient receptor potential polycystin 3 (TRPP3) is a TRP superfamily member. It is a calciumpermeable non-selective cation channel that regulates intracellular calcium concentration and thereby calcium signaling. Although the calmodulin (CaM) inhibitor, calmidazolium, is an activator of the PKD2L1 channel, the activating mechanism remains unclear. The purpose of this study is to clarify whether CaM takes part in the regulation of the PKD2L1 channel, and if so, how. With patch clamp techniques, we observed the current amplitudes of PKD2L1 significantly reduced when coexpressed with $\mathrm{CaM}$ and $\mathrm{CaM} \Delta \mathrm{N}$. This result suggests that the $\mathrm{N}$-lobe of CaM carries a more crucial role in regulating PKD2L1 and guides us into our next question on the different functions of two lobes of CaM. We also identified the predicted CaM binding site, and generated deletion and truncation mutants. The mutants showed significant reduction in currents losing PKD2L1 current-voltage curve, suggesting that the C-terminal region from 590 to 600 is crucial for maintaining the functionality of the PKD2L1 channel. With PKD2L1608Stop mutant showing increased current amplitudes, we further examined the functional importance of EF-hand domain. Along with co-expression of $\mathrm{CaM}, \triangle \mathrm{EF}$-hand mutant also showed significant changes in current amplitudes and potentiation time. Our findings suggest that there is a constitutive inhibition of EF-hand and binding of CaM C-lobe on the channel in low calcium concentration. At higher calcium concentration, calcium ions occupy the N-lobe as well as the EF-hand domain, allowing the two to compete to bind to the channel.

\section{INTRODUCTION}

Polycystic kidney disease 2-like-1 (PKD2L1) has been reported to be regulated by extracellular and intracellular calcium although the response varies depending on different cell types and experiment conditions [1,2]. In our previous study, we have shown the different time courses of the channel activation and inactivation depending on different intracellular calcium concentrations [3]. The roles of PKD2L1 are found to be physiologically crucial for determining the intestinal orientation [4], regulating neuronal excitability [5], and maintaining spine curvature [6]. Along with other transient receptor potential (TRP) channels, the structure of PKD2L1 was also reported recently [7,8]. Although the studies unveil the significance of polycystin domain and the gating mechanisms of the channel, the $\mathrm{N}$ - and C-terminal regions were not structurally resolved. The flexibility of the terminal regions has been a barrier to understanding the functional domains of the channel including coiled-coil domain, EF-hand domain, oligomerization domain, and potentially, calmodulin binding domain. Calmodulin (CaM) is a calcium-binding, highly conserved protein and serves in regulation of a myriad of target proteins, among them being ion channels [9]. The two distinct lobes of CaM, acting as independent calcium sensors, and the long flexible linker in between allow CaM to have various con-
(1) $\$$ This is an Open Access article distributed under the terms of the Creative Commons Attribution Non-Commercial License, which permits unrestricted non-commercial use, distribution, and reproduction in any medium, provided the original work is properly cited. Copyright @ Korean J Physiol Pharmacol, pISSN 1226-4512, eISSN 2093-3827
Author contributions: E.Y.J.P. and J.Y.B. designed and performed the experiments, analyzed data and wrote the paper with I.S.; M.K. performed Western blot analysis. I.S. and E.Y.J.P. discussed the results and implications and commented on the manuscript at all stages. 
formations and effects on the target proteins. The CaM binding site has mostly been identified as the IQ motif or the modified, or a hydrophobic alpha helical sequence $[10,11]$, but also varies depending on the channels.

Calmidazolium (CMZ), which is known as a CaM inhibitor [12], was used as an agonist of PKD2L1 [13]. We have also observed the agonistic effect of $\mathrm{CMZ}$ on the channel in the previous report [3]. However, the mechanism of how CMZ activates is unknown. Another CaM inhibitor known as $N$-(6-aminohexyl)5-chloro-1-naphthalenesulfonamide (W-7) is reported to bind to troponin $\mathrm{C}$ in the presence of calcium and inhibit striated muscle contraction. It also has nonspecific effects, such as blocking of Ltype $\mathrm{Ca}^{2+}, \mathrm{K}^{+}, \mathrm{Na}^{+}$channels, and sarcoplasmic reticulum calciumrelease channels.

\section{METHODS}

\section{Cell culture and transient transfection}

Human embryonic kidney 293 (HEK293) cells (American Type Culture Collection, Manassas, VA, USA) were cultured according to the supplier's recommendations. The cells were seeded in 12-well plates prior to transient transfection. The following day, $0.5 \mu \mathrm{g} /$ well of internal ribosome entry site (IRES) and enhanced green fluorescence protein (EGFP) containing human PKD2L1 was transfected into cells using FuGENE 6 transfection reagent (Roche Molecular Biochemicals, Mannheim, Germany) according to the manufacturer's protocol. For 1 to 1 co-transfection with CaM, $0.5 \mu \mathrm{g} /$ well of pCI-neomycin rat CaM was transfected into cells with human PKD2L1-IRES-EGFP, and for 2:1 co-transfection, $1 \mu \mathrm{g} /$ well was transfected. Within 24 to $48 \mathrm{~h}$, the attached cells were trypsinized and used for patch clamp recordings.

\section{Electrophysiology}

Whole cell currents were recorded using an Axopatch 200B amplifier (Axon Instruments, Foster City, CA, USA). Currents were filtered at $5 \mathrm{kHz}(-3 \mathrm{~dB}, 4$-pole bessel), digitized using a Digidata 1440A Interface (Axon Instruments), and analyzed using a personal computer equipped with pClamp 10.2 software (Axon Instruments) and Origin software (Microcal origin v.8.0; Microcal Software, Northampton, MA, USA). Patch pipettes were made from borosilicate glass and had resistances of 2-3 M $\Omega$ when filled with pipette solutions. From holding potential at -60 $\mathrm{mV}$, voltage ramp pulse was applied from $-100 \mathrm{mV}$ to $100 \mathrm{mV}$ for $500 \mathrm{~ms}$. For whole cell experiments, we used an external bath medium (standard bath solution) of the following composition (in $\mathrm{mM}$ ): $150 \mathrm{NaCl}, 10 \mathrm{~N}$-(2-hydroxyethyl)piperazine- $N$ '-2-ethansulfonic acid (HEPES), $1.8 \mathrm{CaCl}_{2}$, and $1 \mathrm{MgCl}_{2}$ with $\mathrm{pH}$ adjusted to 7.4 using $\mathrm{NaOH}$. The pipette solutions contained (in $\mathrm{mM}$ ): 100 CsMES, $35 \mathrm{NaCl}, 10$ HEPES, 5 cesium-1,2-bis-(2-aminophenoxy) ethane- $N, N, N^{\prime}, N^{\prime}$-tetraacetic acid (Cs-BAPTA), $2 \mathrm{MgCl}_{2} ; 16 \mathrm{nM}$ free $\left[\mathrm{Ca}^{2+}\right], \mathrm{pH} 7.4$. For recording the current responses of the channels to CaM inhibitors, $1 \mu \mathrm{M}$ of CMZ (Calbiochem, San Diego, CA, USA) and $10 \mu \mathrm{M}$ of W-7 (Sigma Aldrich, St. Loius, MO, USA) were used. The diluted solution was made on each day of experiment and any remainder of the solution was discarded after the experiment. Experiments were performed at room temperature $\left(20^{\circ} \mathrm{C}-24^{\circ} \mathrm{C}\right)$.

\section{Western blot}

Cells were plated in 6-well dishes. Lysates were prepared in lysis buffer (0.5\% Triton X-100, $150 \mathrm{mM} \mathrm{NaCl}, 50$ mM HEPES, 2 mM $\mathrm{MgCl}_{2}, 2$ mM EDTA, $\mathrm{pH}$ 7.4) via passage 10-15 times through a 26-gauge needle after sonication. After lysates were centrifuged at $13,000 \times g$ for $10 \mathrm{~min}$ at $4^{\circ} \mathrm{C}$, the protein concentration in the supernatants was determined. The extracted proteins in sample buffer were loaded onto $10 \%$ Tris-glycine sodium dodecyl sulfate polyacrylamide gel electrophoresis gels. The proteins were transferred onto a polyvinylidene fluoride membrane. The membrane was incubated with anti-hemagglutinin (HA) (12CA5; Roche Molecular Biochemicals) and anti- $\beta$-tubulin (T-4026; Sigma Aldrich) overnight at $4^{\circ} \mathrm{C}$.

\section{Prediction of CaM binding site}

The CaM binding site was predicted by Calmodulin Target Database (http://calcium.uhnres.utoronto.ca/ctdb/ctdb/sequence. html), using the protein sequence of human PKD2L1. The result is shown with numerical value. The series of 9 indicate highly significant position.

\section{Statistics}

Results are presented as mean \pm standard error of mean. The data were analyzed using Prism-GraphPad (GraphPad Software, San Diego, CA, USA). Statistical data were compared by paired or unpaired Student's t-test between two groups. The $\mathrm{p}<0.05$ and $\mathrm{p}<0.01$ were considered statistically significant. The number of whole cell recordings is indicated by $\mathrm{n}$.

\section{RESULTS}

\section{PKD2L1 channel is activated by CaM inhibitors}

The PKD2L1 channel has been studied with many agonists among which CMZ is a potent activator of the homomeric channel. Although CMZ is used as an agonist of the PKD2L1 channel $[1,3]$, the mechanism of its activating effect on the channel remains to be elucidated. To examine whether $\mathrm{CMZ}$ acts upon the channel mediated by CaM, we used W-7, which is also known 
as a CaM inhibitor. By performing whole-cell patch clamp on PKD2L1-expressed HEK293 cell, we observed the channel currents increased from $127 \pm 35 \mathrm{pA} / \mathrm{pF}(\mathrm{n}=5)$ to $173 \pm 45 \mathrm{pA} / \mathrm{pF}$ (n $=5$ ) indicated in red (Fig. 1).

\section{PKD2L1 channel currents are reduced by CaM N-lobe}

As we have observed the currents of the PKD2L1 channel increased by CMZ in our previous study [3] and $\mathrm{W}-7$ in the present study, we came to a conclusion that the current increase of the channel is mediated by CaM. As expected, co-expression of PKD2L1 and CaM showed decreased basal currents, as well as decreased effect of CMZ. The I-V curve currents induced by CMZ are indicated in blue and the basal currents in black in Fig. 2AD. The basal currents of PKD2L1 co-expressed with CaM with 1 to 2 ratio were significantly decreased from $58 \pm 9 \mathrm{pA} / \mathrm{pF}(\mathrm{n}=5)$ to $8 \pm 2 \mathrm{pA} / \mathrm{pF}(\mathrm{n}=6)$ (Fig. $2 \mathrm{~B}, \mathrm{E})$ and with 1 to 1 ratio, from $69 \pm$ $11 \mathrm{pA} / \mathrm{pF}(\mathrm{n}=6)$ to $29 \pm 5 \mathrm{pA} / \mathrm{pF}(\mathrm{n}=5)$ (Fig. 2G). The increased currents by CMZ, where the basal currents were subtracted from the CMZ-induced currents, were also reduced from $41 \pm 11 \mathrm{pA} /$ $\mathrm{pF}(\mathrm{n}=6)$ to $6 \pm 5 \mathrm{pA} / \mathrm{pF}(\mathrm{n}=5)$ when co-expressed with 1 to 2 ratio (Fig. $2 \mathrm{~B}, \mathrm{~F}$ ) and from $44 \pm 8 \mathrm{pA} / \mathrm{pF}(\mathrm{n}=4)$ to $24 \pm 11 \mathrm{pA} / \mathrm{pF}(\mathrm{n}$ $=4$ ) when co-expressed with 1 to 1 ratio (Fig. $2 \mathrm{H}$ ).

There are many studies regarding channel proteins that are regulated by $\mathrm{CaM}$ for which each lobe has an independent function [14-16]. To investigate whether each lobe has an independent effect on regulating the PKD2L1 channel, we co-expressed the channel with CaM deletion mutants. When co-expressed with $\mathrm{CaM} \Delta \mathrm{C}$ with 1 to 2 ratio, the channel showed significant decrease in channel amplitudes to $13 \pm 2 \mathrm{pA} / \mathrm{pF}(\mathrm{n}=6)$ (Fig. $2 \mathrm{C}, \mathrm{E})$ and with 1 to 1 ratio, to $28 \pm 7 \mathrm{pA} / \mathrm{pF}(\mathrm{n}=4)$ (Fig. 2G). The increased currents by CMZ were also reduced to $14 \pm 5 \mathrm{pA} / \mathrm{pF}(\mathrm{n}=6)$ when co-expressed with 1 to 2 ratio (Fig. 2C, F) and to $14 \pm 3 \mathrm{pA} / \mathrm{pF}$ (n $=4$ ) when co-expressed with 1 to 1 ratio (Fig. $2 \mathrm{H}$ ). Interestingly, co-expression with $\mathrm{CaM} \Delta \mathrm{N}$ did not alter the basal currents significantly, yielding $31 \pm 11 \mathrm{pA} / \mathrm{pF}(\mathrm{n}=8)$ for 1 to 2 ratio expression (Fig. 2D, E) and $98 \pm 9 \mathrm{pA} / \mathrm{pF}(\mathrm{n}=6)$ for 1 to 1 ratio expression (Fig. 2G). The increased currents by CMZ were significantly reduced to $12 \pm 6 \mathrm{pA} / \mathrm{pF}(\mathrm{n}=8)$ for 1 to 2 ratio expression (Fig. $2 \mathrm{D}, \mathrm{F})$ and to $44 \pm 10 \mathrm{pA} / \mathrm{pF}(\mathrm{n}=4)$ for 1 to 1 ratio expression (Fig. $2 \mathrm{H})$. These results suggest that the PKD2L1 channel is regulated and inhibited by $\mathrm{CaM}$ and specifically by the N-lobe.

\section{Intracellular calcium in the presence of CaM delays the time course of the channel potentiation}

In our previous study, we have shown the different time courses of the channel potentiation and inactivation under different intracellular calcium concentration [3]. Since CaM is a calciumregulated protein, we examined whether changes in intracellular calcium concentration alter the potentiation and inactivation characteristics of the channel when co-expressed with CaM. Surprisingly, in the presence of over-expressed CaM, the peak currents of the channel with $16 \mathrm{nM}$ and $100 \mathrm{nM}$ free $\mathrm{Ca}^{2+}$ was significantly reduced from $175 \pm 37 \mathrm{pA} / \mathrm{pF}(\mathrm{n}=10)$ to $18 \pm 5 \mathrm{pA} /$ $\mathrm{pF}(\mathrm{n}=4)$ and from $301 \pm 50 \mathrm{pA} / \mathrm{pF}(\mathrm{n}=5)$ to $55 \pm 27 \mathrm{pA} / \mathrm{pF}(\mathrm{n}$ $=5$ ), respectively (Fig. $3 \mathrm{G}$ ). However, the potentiation time of the channel with $16 \mathrm{nM}$ free $\mathrm{Ca}^{2+}$ showed no significant difference, yielding $405 \pm 56 \mathrm{sec}(\mathrm{n}=8)$ for PKD2L1 and $395 \pm 43 \mathrm{sec}(\mathrm{n}=4)$ for CaM co-expression (Fig. 3H). With $100 \mathrm{nM}$ free $\mathrm{Ca}^{2+}$, the po-
A

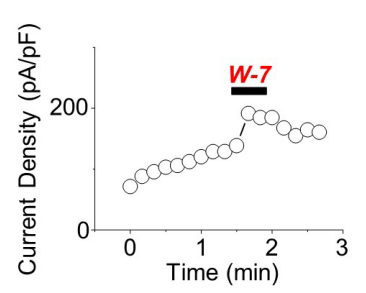

B

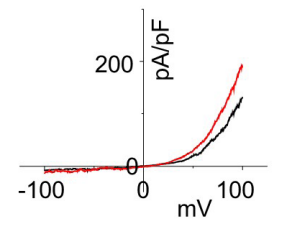

C

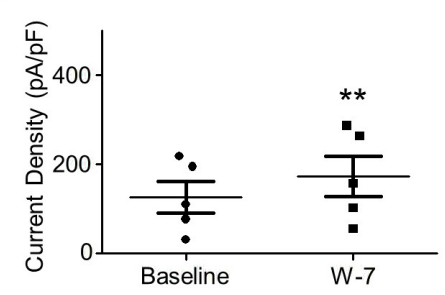

D

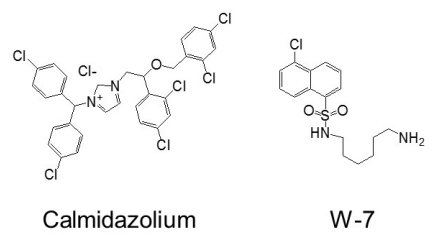

Fig. 1. The effect of W-7 on polycystic kidney disease 2-like-1 (PKD2L1) current. (A) A full current trace of PKD2L1 activation induced by $10 \mu M$ of $\mathrm{N}$-(6-aminohexyl)-5-chloro-1-naphthalenesulfonamide (W-7) measured in a PKD2L1-expressed human embryonic kidney 293 cell using wholecell patch clamp technique. From the holding potential at $-60 \mathrm{mV}$, ramp pulse was applied from $-100 \mathrm{mV}$ to $100 \mathrm{mV}$. (B) The current (I)-voltage (V) relationship of PKD2L1. The I-V curve demonstrates outward rectification of the channel. Each colored line indicates I-V relationship at the basal current amplitude (black) and at the application of W-7 (red), respectively. (C) A summarized current amplitude of PKD2L1 induced by W-7. (D) Molecular structures of CMZ and W-7. They are both amphipathic weak bases. ${ }^{* *} \mathrm{p}<0.01$. 
A
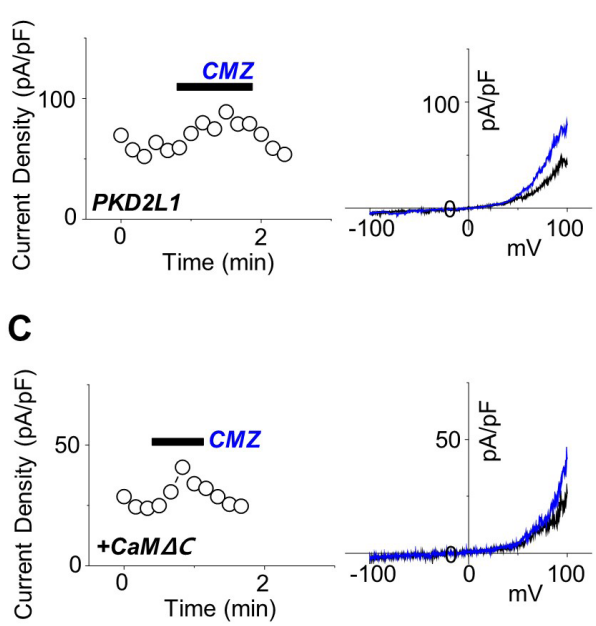

E

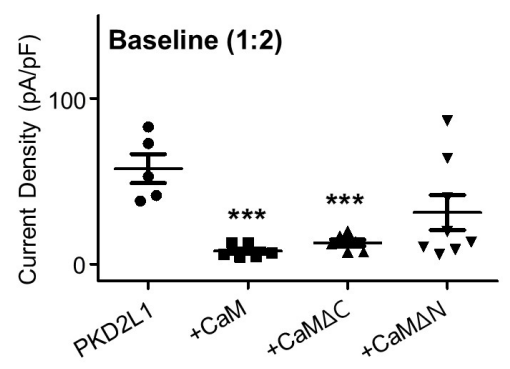

G

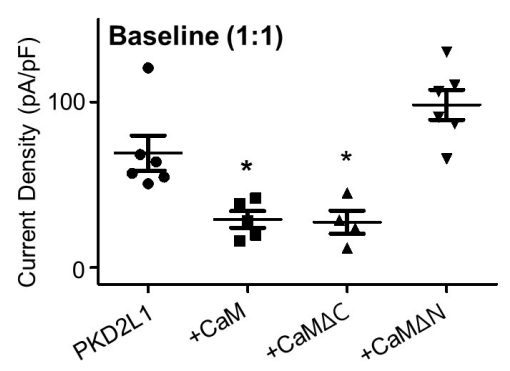

B

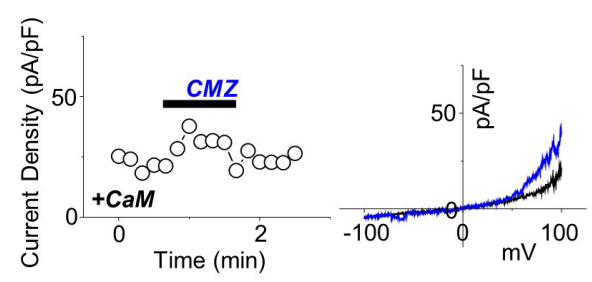

D

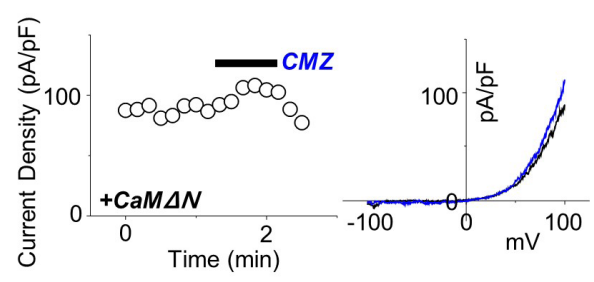

$\mathbf{F}$

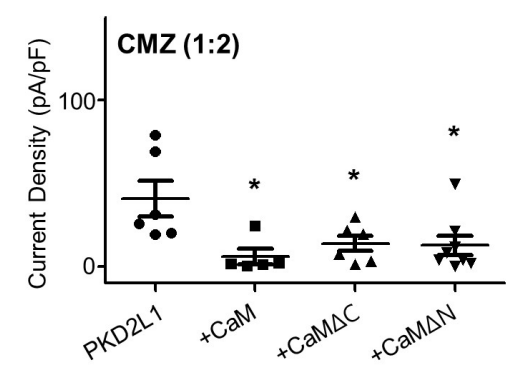

H

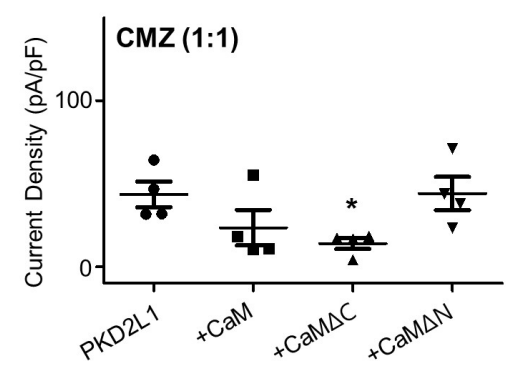

Fig. 2. The effect of co-expression with calmodulin ( $\mathrm{CaM}$ ) and its deletion mutants on polycystic kidney disease 2-like-1 (PKD2L1) current. (A) A full current trace of PKD2L1 (left) activated by $1 \mu \mathrm{M}$ of calmidazolium (CMZ) and the I-V relationship of PKD2L1 (right) at the basal current amplitude (black) and at the application of $1 \mu \mathrm{M}$ of CMZ (blue). (B) A full current trace (left) and I-V relationship (right) of PKD2L1, co-expressed with CaM with 1:2 ratio, activated by CMZ. Blue line indicates $I-V$ relationship at the application of CMZ. (C) A full current trace (left) and I-V relationship (right) of PKD2L1, co-expressed with CaM $\Delta C$ with $1: 2$ ratio, activated by $C M Z$. Blue line indicates I-V relationship at the application of CMZ. (D) A full current trace (left) and I-V relationship (right) of PKD2L1, co-expressed with CaM $\Delta \mathrm{N}$ with 1:2 ratio, activated by $C M Z$. Blue line indicates $I-V$ relationship at the application of CMZ. (E) A summarized basal current amplitude of PKD2L1, PKD2L1 with CaM, PKD2L1 with $\mathrm{CaM} \triangle \mathrm{C}$, and PKD2L1 with $\mathrm{CaM} \triangle \mathrm{N}$ with 1:2 expression ratio. (F) A summarized increased current amplitude of CMZ-induced PKD2L1, PKD2L1 with CaM, PKD2L1 with $\mathrm{CaM} \Delta \mathrm{C}$, and PKD2L1 with CaM $\Delta N$ with 1:2 expression ratio. (G) A summarized basal current amplitude of PKD2L1, PKD2L1 with CaM, PKD2L1 with $\mathrm{CaM} \triangle \mathrm{C}$, and PKD2L1 with $\mathrm{CaM} \triangle \mathrm{N}$ with 1:1 expression ratio. $(\mathrm{H}) \mathrm{A}$ summarized increased current amplitude of CMZinduced PKD2L1, PKD2L1 with CaM, PKD2L1 with CaM $\triangle C$, and PKD2L1 with $\mathrm{CaM} \Delta \mathrm{N}$ with 1:1 expression ratio. ${ }^{*} \mathrm{p}<$ $0.05,{ }^{* * *} \mathrm{p}<0.001$. tentiation time of the channel increased from $218 \pm 38 \mathrm{sec}(\mathrm{n}=5)$ to $503 \pm 47 \mathrm{sec}(\mathrm{n}=4)$ (Fig. $3 \mathrm{H})$. With $500 \mathrm{nM}$ free $\mathrm{Ca}^{2+}$, there was no significant change in the peak currents and the potentiation time, yielding from $93 \pm 22 \mathrm{pA} / \mathrm{pF}(\mathrm{n}=9)$ to $114 \pm 45 \mathrm{pA} / \mathrm{pF}(\mathrm{n}=4)$ and from $124 \pm 39 \mathrm{sec}(\mathrm{n}=9)$ to $183 \pm 49 \mathrm{sec}(\mathrm{n}=4)$, respectively (Fig. 3G, H).

\section{Putative CaM-binding domain is crucial for PKD2L1 channel functionality}

To investigate the binding domain of CaM in PKD2L1, we used Calmodulin Target Database with the protein sequence of human PKD2L1. The result shows that the protein sequences from K590 to E600 are highly significant region for CaM binding (Supplementary Fig. 1). Based on this result, we generated PKD2L1 mu- tants where selective amino acids were deleted or substituted with alanine or truncated [10]. As shown in Fig. 4C and Supplementary Fig. 2A-D, $\Delta 590-600$, L592/597E, RRRK/AAAA, and 588Stop mutants lost PKD2L1 characteristics of I-V curve, exhibiting significant reduction in channel activity to $9 \pm 1 \mathrm{pA} / \mathrm{pF}(\mathrm{n}=7), 13$ $\pm 3 \mathrm{pA} / \mathrm{pF}(\mathrm{n}=13), 11 \pm 1 \mathrm{pA} / \mathrm{pF}(\mathrm{n}=12)$, and $11 \pm 1 \mathrm{pA} / \mathrm{pF}(\mathrm{n}=$ 4 ), respectively. While the mutants had no response to CMZ, they showed increased currents induced by $100 \mu \mathrm{M}$ of 8 -Br-cAMP treatment (Supplementary Fig. 2E, F). We observed that the channel characteristics of 600Stop and 608Stop truncation mutants were intact and the currents were increased by CMZ from $27 \pm 8$ $\mathrm{pA} / \mathrm{pF}(\mathrm{n}=5)$ to $51 \pm 11 \mathrm{pA} / \mathrm{pF}(\mathrm{n}=5)($ Fig. $4 \mathrm{~A})$ and from $87 \pm 16$ $\mathrm{pA} / \mathrm{pF}(\mathrm{n}=4)$ to $166 \pm 40 \mathrm{pA} / \mathrm{pF}(\mathrm{n}=4)($ Fig. $4 \mathrm{~B})$, respectively. The baseline currents are indicated in black and CMZ-induced currents in blue in Fig. 4. Surprisingly, the basal currents of 608Stop 
A

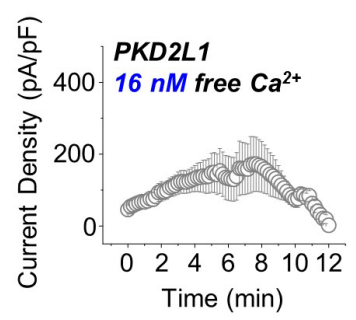

D

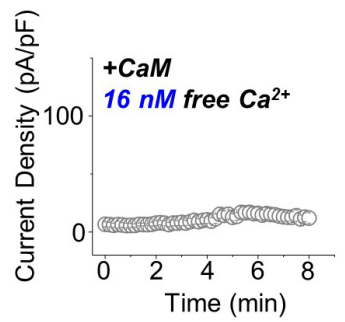

B

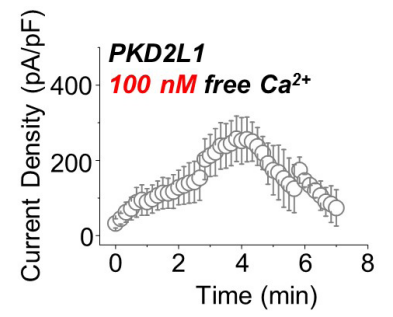

E

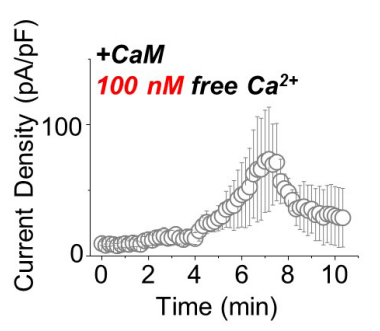

C

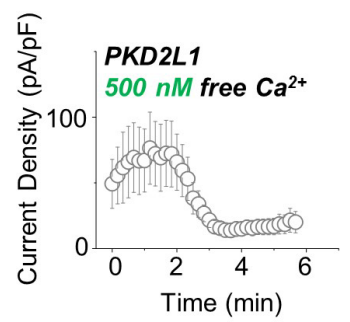

F

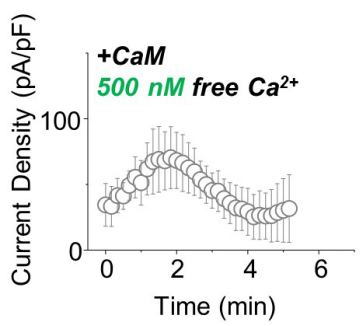

G

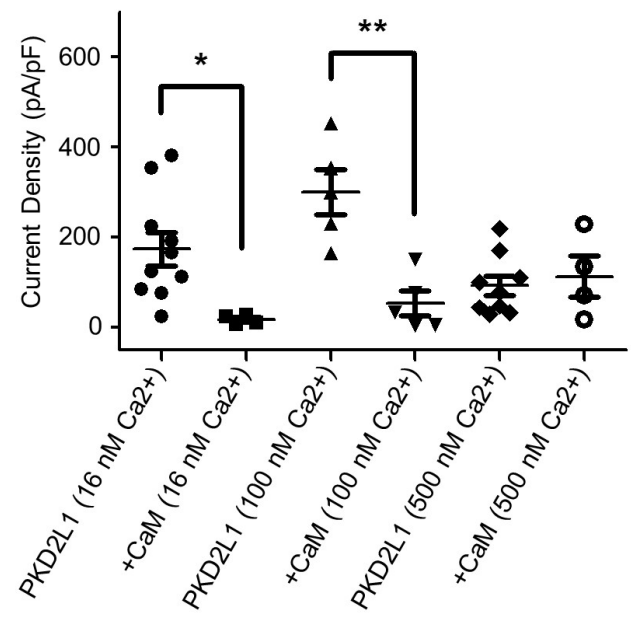

H

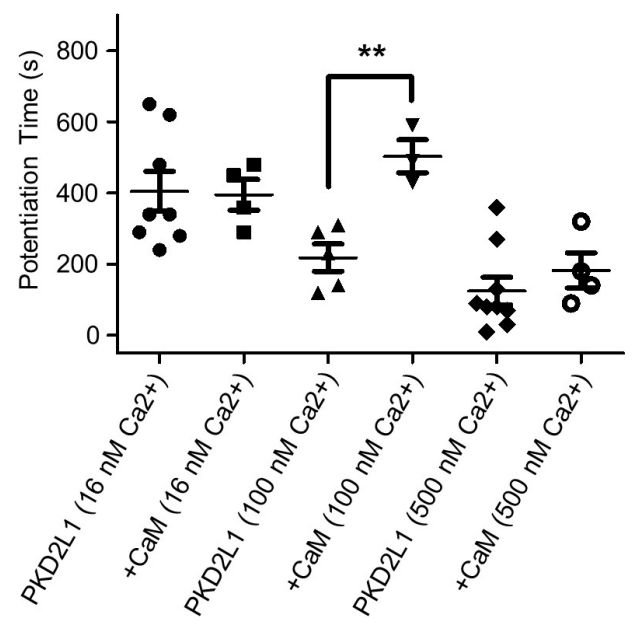

Fig. 3. The potentiation and inactivation of the channel with over-expression of calmodulin (CaM) under different intracellular free calcium concentrations. (A) A full current trace of polycystic kidney disease 2-like-1 (PKD2L1) measured under $16 \mathrm{nM}$ free calcium condition. (B) A full current trace of PKD2L1 measured under $100 \mathrm{nM}$ free calcium condition. (C) A full current trace of PKD2L1 measured under $500 \mathrm{nM}$ free calcium condition. (D) A full current trace of PKD2L1 measured under 16 nM free calcium condition in a PKD2L1- and CaM-expressed human embryonic kidney 293 (HEK293) cell. (E) A full current trace of PKD2L1 measured under $100 \mathrm{nM}$ free calcium condition in a PKD2L1- and CaM-expressed HEK293 cell. (F) A full current trace of PKD2L1 measured under $500 \mathrm{nM}$ free calcium condition in a PKD2L1- and CaM-expressed HEK293 cell. (G) A summarized peak current of PKD2L1 and the channel co-expressed with CaM under 16, 100, $500 \mathrm{nM}$ free $\mathrm{Ca}^{2+}$ condition. $(\mathrm{H}) \mathrm{A}$ summarized peak time of PKD2L1 and the channel co-expressed with CaM under 16, 100, $500 \mathrm{nM}$ free $\mathrm{Ca}^{2+}$ condition. ${ }^{*} \mathrm{p}<0.05,{ }^{* *} \mathrm{p}<0.01$.

were significantly increased while 600Stop showed similar basal currents with that of PKD2L1 ${ }^{\mathrm{WT}}$ (Fig. 4C). To examine the expression pattern of each mutant, we performed Western blot analysis with HA antibodies using lysates of HEK293 cells expressing human PKD2L1 (Fig. 4D). The result showed that the expression of PKD2L1 ${ }^{\mathrm{WT}}$ (92 kDa), L592/597E (92 kDa), RRRK/AAAA (92 kDa; R594A, R596A, R598A, R599A), $\Delta 590-600$ (90.6 kDa) and $600 \mathrm{Stop}(68.8 \mathrm{kDa})$ did not differ greatly, but the expression level of $608 \mathrm{Stop}(69.8 \mathrm{kDa})$ was greatly reduced.
To examine the phenomenon of increased currents in 608Stop mutant, we generated EF-hand deletion mutant $(\triangle \mathrm{EF})$. The peak currents of the $\Delta \mathrm{EF}$ mutant channel with 16 and $500 \mathrm{nM}$ free $\mathrm{Ca}^{2+}$ showed significant increases yielding $481 \pm 89 \mathrm{pA} / \mathrm{pF}(\mathrm{n}=6)$ and $373 \pm 63 \mathrm{pA} / \mathrm{pF}(\mathrm{n}=5)$, respectively (Fig. $5 \mathrm{~A}, \mathrm{C}, \mathrm{D})$. However, the peak currents and the potentiation time of the mutant channel with $100 \mathrm{nM}$ free $\mathrm{Ca}^{2+}$ showed no significant difference yielding $291 \pm 57 \mathrm{pA} / \mathrm{pF}(\mathrm{n}=4)$ and $223 \pm 53 \mathrm{sec}(\mathrm{n}=4)$, respectively (Fig. $5 \mathrm{~B}, \mathrm{D}, \mathrm{E})$. The potentiation time of $\Delta \mathrm{EF}$ mutant channel with 16 

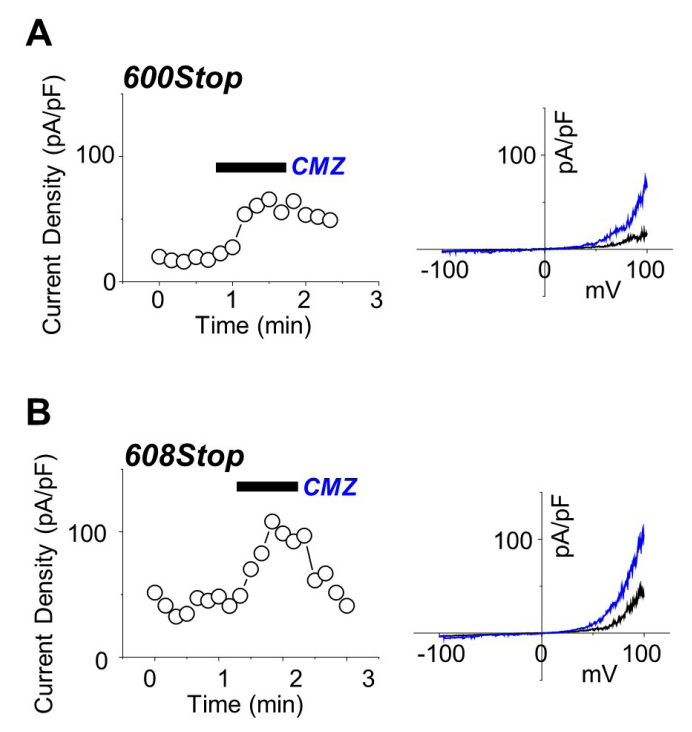

C
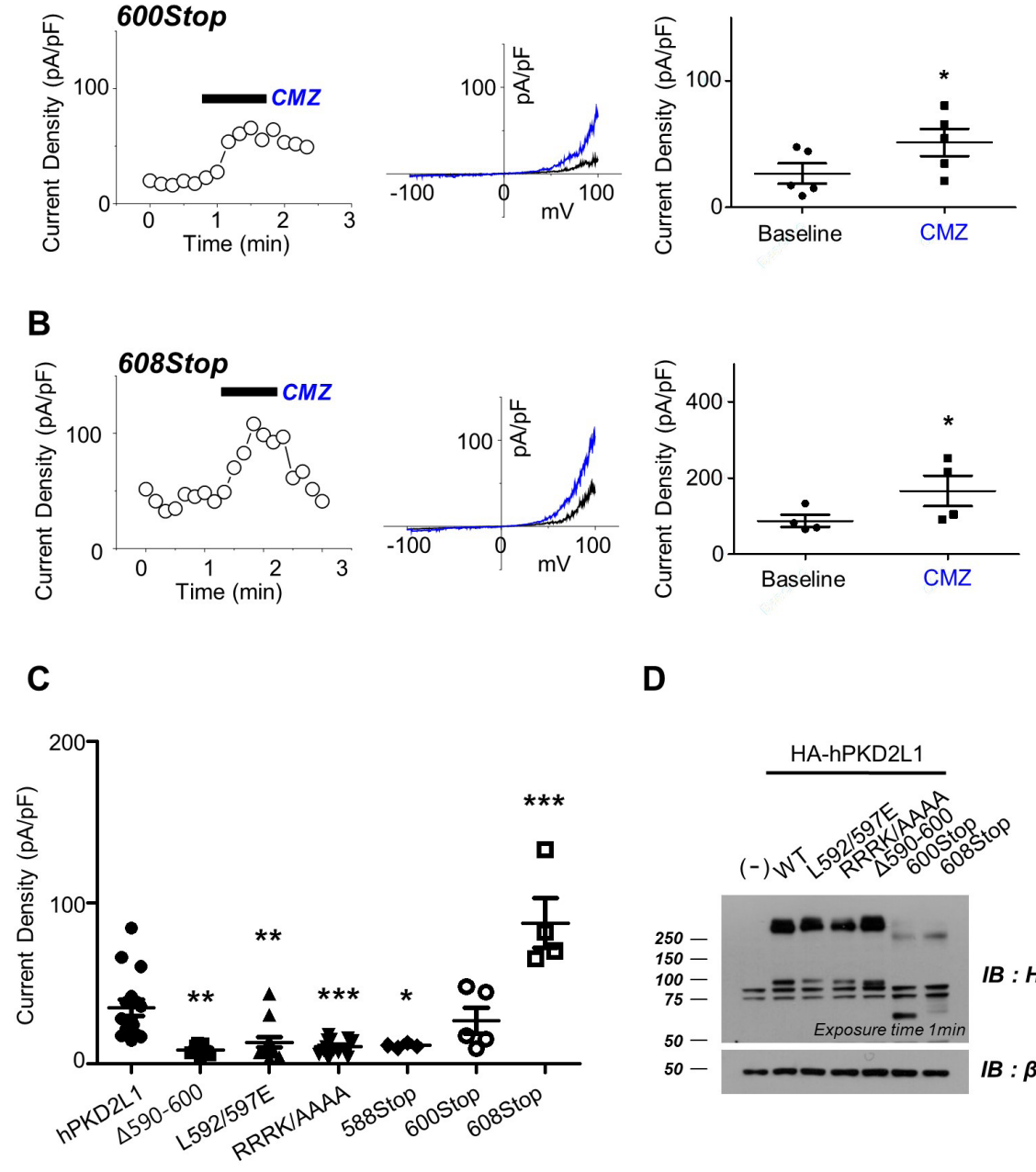

D

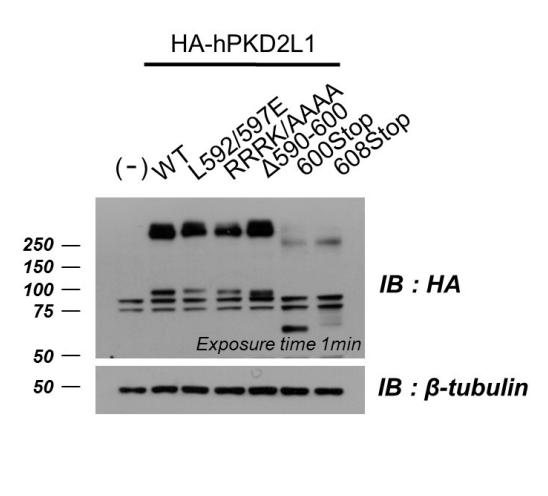

E

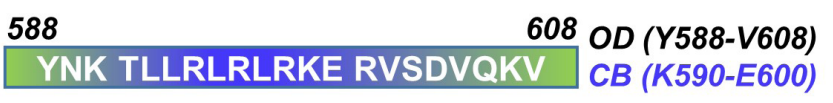

Fig. 4. The loss of function in the putative calmodulin (CaM)-binding domain mutants. (A) A full current trace (left), I-V relationship (middle), and a summarized current amplitude (right) of polycystic kidney disease 2-like-1 (PKD2L1)600Stop activated by calmidazolium (CMZ) (blue). (B) A full current trace (left), I-V relationship (middle), and a summarized current amplitude (right) of PKD2L1608Stop activated by CMZ (blue). (C) A summarized basal current of PKD2L1 and its mutants. (D) The expression pattern of PKD2L1 and its mutants analyzed by Western blotting. (E) Protein sequence between 588 and 608 where functional domains are located. WT, wild type; OD, oligomerization domain; IB, immunoblot. ${ }^{*} p<0.05,{ }^{* *} p<0.01,{ }^{* * *} p$ $<0.001$.
$\mathrm{nM}$ free $\mathrm{Ca}^{2+}$ was significantly reduced yielding $222 \pm 33 \mathrm{sec}(\mathrm{n}=$ 5) and increased with $500 \mathrm{nM}$ calcium yielding $280 \pm 32 \mathrm{sec}(\mathrm{n}=5)$ (Fig. 5A, C, E).

\section{DISCUSSION}

Since our previous study, we have used CMZ as an agonist of PKD2L1 channel. Knowing that CMZ is an inhibitor of CaM, we were interested to investigate on the relationship between CaM protein and the channel. To verify that the activation of the channel is mediated by the inhibition of CaM, we used another CaM inhibitor, W-7, which has a similar property to that of CMZ (Fig. 1D). They are both membrane-permeable amphipathic weak bases. Since W-7 inhibits CaM by blocking the hydrophobic binding pocket of the protein with the aromatic rings [17], we can infer the similar blocking mechanism for CMZ. As expected,
W-7 significantly increased the currents of the PKD2L1 channel, supporting that CMZ- or W-7-induced activation of the channel is mediated by CaM. In agreement with the result, co-expression with CaM significantly reduced the channel currents. To examine whether each lobe of CaM takes different roles, we have used $\mathrm{CaM} \Delta \mathrm{C}$ and $\mathrm{CaM} \Delta \mathrm{N}$. Interestingly, only $\mathrm{CaM} \Delta \mathrm{C}$ significantly reduced basal currents of the channel while $\mathrm{CaM} \Delta \mathrm{N}$ did not alter the current amplitudes. To reinforce reliability cause, we had two different DNA ratios for transfection: one set is transfected with equal amounts of PKD2L1 and CaM DNA and the other set is with a 1 to 2 ratio. These results suggest that the binding mechanism is similar to that of voltage-gated sodium $\left(\mathrm{Na}_{\mathrm{v}}\right)$ and smallconductance $\mathrm{Ca}^{2+}$-activated $\mathrm{K}^{+}$(SK) channel $[15,16]$.

CaM has been studied extensively as one of the important modulators of ion channels [9,14-16,18-21]. One of many structural studies of ion channel elaborates the regulation of $\mathrm{Na}_{\mathrm{v}}$ channel by interaction with $\mathrm{Ca}^{2+} / \mathrm{CaM}$ at $\mathrm{C}$-terminal domain (CTD) 
A

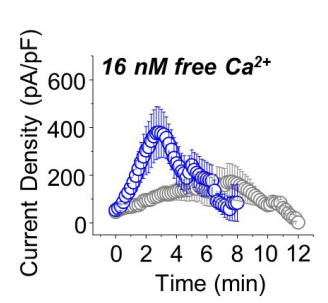

B

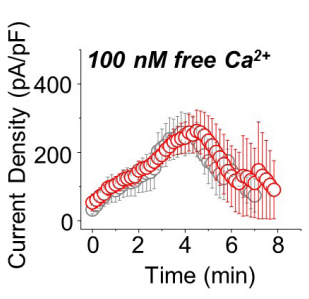

C

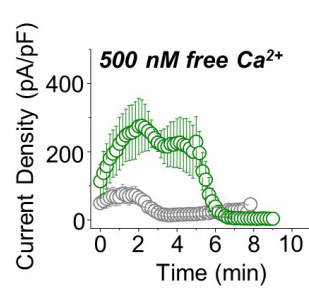

D

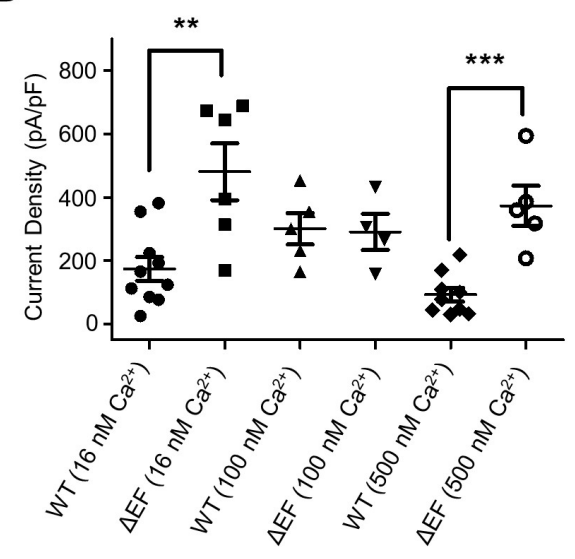

E

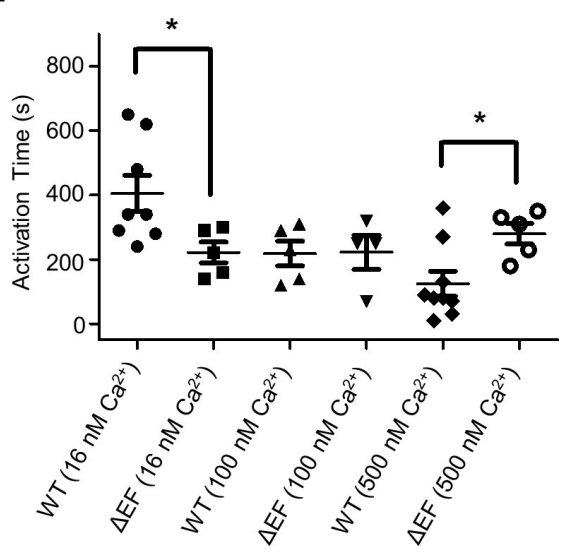

Fig. 5. The potentiation and inactivation of the polycystic kidney disease 2-like-1 (PKD2L1) $\Delta$ EF mutant channel under different intracellular free calcium concentration. (A) A full current trace of PKD2L1 (gray) and $\triangle \mathrm{EF}$ mutant (blue) measured under $16 \mathrm{nM}$ free calcium condition. (B) A full current trace of PKD2L1 (gray) and $\triangle \mathrm{EF}$ mutant (red) measured under $100 \mathrm{nM}$ free calcium condition. (C) A full current trace of PKD2L1 (gray) and $\triangle \mathrm{EF}$ mutant (green) measured under $500 \mathrm{nM}$ free calcium condition. (D) A summarized peak current of PKD2L1 and $\triangle E F$ mutant with 16, $100,500 \mathrm{nM}$ free $\mathrm{Ca}^{2+}$. (E) A summarized peak time of PKD2L1 and $\triangle E F$ mutant with 16, 100, $500 \mathrm{nM}$ free $\mathrm{Ca}^{2+}$. WT, wild type. ${ }^{*} p<0.05,{ }^{* *} p<0.01,{ }^{* * *} p<0.001$.

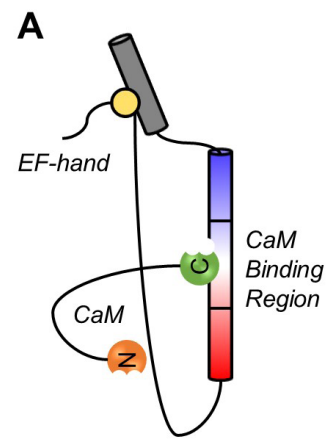

$0 \mathrm{nM}$ free $\mathrm{Ca}^{2+}$

EF-hand Inhibition
B

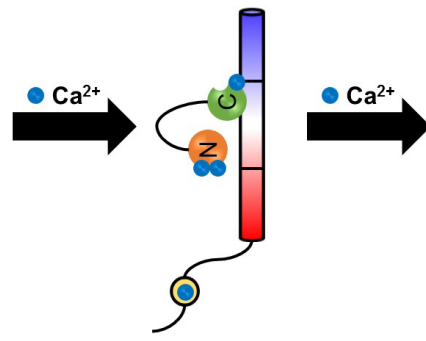

$16 \mathrm{nM}$ free $\mathrm{Ca}^{2+}$

Weak CaM Inhibition
C

D

Fig. 6. A schematic drawing of the predicted mechanism by which calmodulin (CaM) regulates polycystic kidney disease 2-like-1 channel. (A) Under $0 \mathrm{nM}$ or basal levels of calcium (blue), EF-hand (yellow) binds to the channel, constantly inhibiting and CaM remains bound to the channel exerting weak inhibition. The CaM binding peptide is indicated with a color gradient where $\mathrm{N}$-terminus is colored in blue and C-terminus in red. (B) As the calcium levels rise, the EF-hand binds to calcium releasing the channel thereby promoting channel potentiation and CaM C-lobe (green) remains bound to the channel. (C) As the concentration of internal calcium reaches to $100 \mathrm{nM}$, both inhibition by CaM N-lobe (orange) and potentiation by release of EF-hand are exerted on the channel. (D) At higher concentration of calcium, EF-hand that has similar protein sequence to the N-lobe of CaM binds to the channel competing against the N-lobe of CaM.

[16]. The study suggests that CaM binds to IQ domain of CTD. For both $\mathrm{Na}_{v} 1.2$ and $\mathrm{Na}_{v} 1.5$, the channel binds to C-lobe of CaM in the absence of calcium, whereas in the presence of calcium, the channel binds to both lobes of CaM. The study also reports that there were only minor conformational changes to "semi-open" form caused by the binding of C-lobe in the presence of calcium. As expected from CaM C-lobe binding to the channel, the Clobe has lower affinity to calcium ions than that of N-lobe. The
CaM protein is known to have higher affinity to $\mathrm{Ca}^{2+}$ ions in its C-lobe, but the binding to a target protein reduces the affinity in the $\mathrm{Na}_{\mathrm{v}}$ channel. The subsequent binding of CaM N-lobe, which is fully occupied with calcium ions, gives "closed" conformational changes of the channel. The regulation of a SK channel by CaM binding has been studied by electrophysiology and structural analyses $[15,22]$. The results elucidate the mechanism where the $\mathrm{C}$-lobe of CaM is constitutively bound to the channel in the ab- 
A

$\begin{array}{cc}\text { PKD2L1 } & \text { EITELTATFTKFDRDGNRILDEKEQEKMRQDL } 665 \\ \text { CaM(EF2) } & \text { DADGNGTIDFPE } \\ \text { CaM(EF1) } & \text { DKDGDGTITTKE } \\ \text { CaM(EF3) } & \text { DKDGNGYISAAE } \\ \text { CaM(EF4) } & \text { DIDGDGQVNYEE }\end{array}$

B

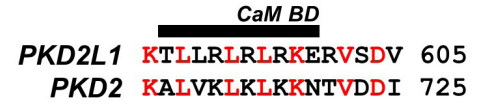

C

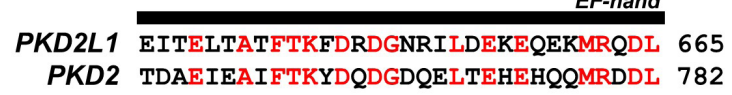

Fig. 7. Protein sequence alignment of polycystic kidney disease 2-like-1 (PKD2L1) with PKD2 and EF-hand domains of calmodulin (CaM). (A) An alignment of PKD2L1 and CaM EF-hand domains with identical residues indicated in red. (B) An alignment of the PKD2L1 and PKD2 CaM binding domain (BD) with identical residues indicated in red. (C) An alignment of the PKD2L1 and PKD2 EF-hand domain with identical residues indicated in red.

sence of calcium and in the presence of calcium, the N-lobe rearranges its structure to a more open conformation, then binding to the channel. The distinct difference in the roles of $\mathrm{N}$ - and C-lobe of $\mathrm{CaM}$ and the binding mechanism may be similar to that of the $\mathrm{Na}_{\mathrm{v}}$ channel. SK channel is rather opened and activated by the binding of N-lobe CaM while $\mathrm{Na}_{\mathrm{v}}$ channel is closed and inactivated. The results we have observed in the present study, where coexpression with $\mathrm{CaM}$ or $\mathrm{CaM} \Delta \mathrm{C}$ reduced the channel currents, support the mechanism similar to that of the $\mathrm{Na}_{\mathrm{v}}$ channel.

For it is well-known that $\mathrm{CaM}$ is a calcium binding protein, we also examined the channel response to different free calcium concentrations when co-expressed with CaM. Surprisingly, the channel currents were significantly reduced with 16 and 100, but not with $500 \mathrm{nM}$ free $\mathrm{Ca}^{2+}$ (Fig. 3G). The potentiation time of the channel with $100 \mathrm{nM}$ free calcium was increased (Fig. 3H). Along with the results from Fig. 5D where the $\triangle \mathrm{EF}$ mutant currents were increased with 16 and 500 but not with $100 \mathrm{nM}$ free $\mathrm{Ca}^{2+}$, we suggest that both $\mathrm{CaM}$ and EF-hand take part in regulating the channel but with different calcium affinities. The actions of calcium on CaM and EF-hand in a channel protein has been studied suggesting that $\mathrm{Ca}^{2+} / \mathrm{CaM}$ releases the binding domain of the channel and let $\mathrm{Ca}^{2+} / \mathrm{EF}-$ hand interact with the domain $[23,24]$. We suggest that in the absence of calcium, EF-hand constantly binds and constantly exerts inhibitory effects on the channel (Fig. $6 \mathrm{~A})$, but in the presence of calcium, it releases while CaM binds and inhibits the channel activity (Fig. 6B). At higher concentration or $500 \mathrm{nM}$ free $\mathrm{Ca}^{2+}, \mathrm{Ca}^{2+} / \mathrm{CaM}$ loses affinity to the channel and $\mathrm{Ca}^{2+} / \mathrm{EF}$-hand binds to the CaM binding domain, inhibiting the channel (Fig. 6D). An alignment of the protein sequences of the channel and EF-hand domains of CaM (Fig. 7A) demonstrates higher similarity of $\mathrm{CaM}$ (EF2) to the channel supporting the competing mechanism of CaM N-lobe and EF-hand domain of the channel. The fact that the protein sequences of CaM binding domain and EF-hand domain in PKD2L1 are also conserved in PKD2 with high similarity further accentuates the importance of our findings in this study (Fig. 7B, C).

The EF-hand domain is located at 633-668 (human) and earlier found to be not related to calcium-induced activation of the channel [1]. Although not thoroughly explained, the report also shows increased and rather unstable currents of the EF-hand truncation mutant. In this study, we observed significant changes in current amplitudes and potentiation time in $\triangle \mathrm{EF}$ mutant channel with adjusted calcium concentrations.

To investigate the CaM-binding domain within the channel, we used Calmodulin Target Database that provides a prediction program. As a result, the putative binding domain was located at the C-terminal region of the channel from K590 to E600. Consequently, the mutants were generated based on the report from Zhu [10]. Although we expected that CaM would not be able to bind to the mutants thereby increasing the currents, the results demonstrated a loss of functionality for each mutant except for 600Stop and 608Stop. One possible explanation for this is that the putative CaM-binding domain may contain other functional domains [25]. One report suggests that the region that overlaps with the putative CaM domain (Fig. $4 \mathrm{E}$ ) is responsible for strong homomerization of the channel. However, this view has recently been challenged by studies by cryo-EM where the truncated constructs were structurally stable $[7,8,26]$. We suggest that the region is responsible for interaction with other domains of the channel to form a proper binding domain for $\mathrm{CaM}$.

\section{ACKNOWLEDGEMENTS}

We thank Dr. Markus Delling (UCSF) for kindly donating human PKD2L1 constructs and Prof. Kyupil Lee for kindly donating CaM deletion mutants. This research project was supported by BK21-plus education program of the MOE (Ministry of Education) by the National Research Foundation of Korea, and NRF grant funded by the Korea government (2018R1A4A1023822).

\section{CONFLICTS OF INTEREST}

The authors declare no conflicts of interest.

\section{SUPPLEMENTARY MATERIALS}

Supplementary data including two figures can be found with this article online at http://pdf.medrang.co.kr/paper/pdf/Kjpp/ 
Kjpp2019-23-03-06-s001.pdf.

\section{REFERENCES}

1. DeCaen PG, Liu X, Abiria S, Clapham DE. Atypical calcium regulation of the PKD2-L1 polycystin ion channel. Elife. 2016;5:e13413.

2. Chen XZ, Vassilev PM, Basora N, Peng JB, Nomura H, Segal Y, Brown EM, Reeders ST, Hediger MA, Zhou J. Polycystin-L is a calcium-regulated cation channel permeable to calcium ions. Nature. 1999;401:383-386.

3. Park EYJ, Kwak M, Ha K, So I. Identification of clustered phosphorylation sites in PKD2L1: how PKD2L1 channel activation is regulated by cyclic adenosine monophosphate signaling pathway. Pflugers Arch. 2018;470:505-516.

4. Delling M, DeCaen PG, Doerner JF, Febvay S, Clapham DE. Primary cilia are specialized calcium signalling organelles. Nature. 2013;504:311-314.

5. Yao G, Luo C, Harvey M, Wu M, Schreiber TH, Du Y, Basora N, Su X, Contreras D, Zhou J. Disruption of polycystin-L causes hippocampal and thalamocortical hyperexcitability. Hum Mol Genet. 2016;25:448-458.

6. Sternberg JR, Prendergast AE, Brosse L, Cantaut-Belarif Y, Thouvenin O, Orts-Del'Immagine A, Castillo L, Djenoune L, Kurisu S, McDearmid JR, Bardet PL, Boccara C, Okamoto H, Delmas P, Wyart C. Pkd2l1 is required for mechanoception in cerebrospinal fluid-contacting neurons and maintenance of spine curvature. Nat Commun. 2018;9:3804.

7. Su Q, Hu F, Liu Y, Ge X, Mei C, Yu S, Shen A, Zhou Q, Yan C, Lei J, Zhang Y, Liu X, Wang T. Cryo-EM structure of the polycystic kidney disease-like channel PKD2L1. Nat Commun. 2018;9:1192.

8. Hulse RE, Li Z, Huang RK, Zhang J, Clapham DE. Cryo-EM structure of the polycystin 2-11 ion channel. Elife. 2018;7:e36931.

9. Saimi Y, Kung C. Calmodulin as an ion channel subunit. Annu Rev Physiol. 2002;64:289-311.

10. Zhu MX. Multiple roles of calmodulin and other $\mathrm{Ca}^{2+}$-binding proteins in the functional regulation of TRP channels. Pflugers Arch. 2005;451:105-115.

11. Rhoads AR, Friedberg F. Sequence motifs for calmodulin recognition. FASEB J. 1997;11:331-340.

12. Sunagawa M, Kosugi T, Nakamura M, Sperelakis N. Pharmacological actions of calmidazolium, a calmodulin antagonist, in cardiovascular system. Cardiovasc Drug Rev. 2000;18:211-221.

13. DeCaen PG, Delling M, Vien TN, Clapham DE. Direct recording and molecular identification of the calcium channel of primary cilia. Nature. 2013;504:315-318.

14. Singh AK, McGoldrick LL, Twomey EC, Sobolevsky AI. Mechanism of calmodulin inactivation of the calcium-selective TRP channel TRPV6. Sci Adv. 2018;4:eaau6088.

15. Lee $\mathrm{CH}$, MacKinnon R. Activation mechanism of a human SKcalmodulin channel complex elucidated by cryo-EM structures. Science. 2018;360:508-513.

16. Wang C, Chung BC, Yan H, Wang HG, Lee SY, Pitt GS. Structural analyses of $\mathrm{Ca}^{2+} / \mathrm{CaM}$ interaction with $\mathrm{NaV}$ channel C-termini reveal mechanisms of calcium-dependent regulation. Nat Commun. 2014;5:4896.

17. Osawa M, Swindells MB, Tanikawa J, Tanaka T, Mase T, Furuya T, Ikura M. Solution structure of calmodulin-W-7 complex: the basis of diversity in molecular recognition. J Mol Biol. 1998;276:165-176.

18. Hughes TET, Pumroy RA, Yazici AT, Kasimova MA, Fluck EC, Huynh KW, Samanta A, Molugu SK, Zhou ZH, Carnevale V, Rohacs T, Moiseenkova-Bell VY. Structural insights on TRPV5 gating by endogenous modulators. Nat Commun. 2018;9:4198.

19. Hasan R, Zhang X. $\mathrm{Ca}^{2+}$ Regulation of TRP ion channels. Int J Mol Sci. 2018;19:1256.

20. Lau SY, Procko E, Gaudet R. Distinct properties of $\mathrm{Ca}^{2+}$-calmodulin binding to $\mathrm{N}$ - and C-terminal regulatory regions of the TRPV1 channel. J Gen Physiol. 2012;140:541-555.

21. Lishko PV, Procko E, Jin X, Phelps CB, Gaudet R. The ankyrin repeats of TRPV1 bind multiple ligands and modulate channel sensitivity. Neuron. 2007;54:905-918.

22. Keen JE, Khawaled R, Farrens DL, Neelands T, Rivard A, Bond CT, Janowsky A, Fakler B, Adelman JP, Maylie J. Domains responsible for constitutive and $\mathrm{Ca}^{2+}$-dependent interactions between calmodulin and small conductance $\mathrm{Ca}^{2+}$-activated potassium channels. $J$ Neurosci. 1999;19:8830-8838.

23. Shah VN, Wingo TL, Weiss KL, Williams CK, Balser JR, Chazin WJ. Calcium-dependent regulation of the voltage-gated sodium channel hH1: intrinsic and extrinsic sensors use a common molecular switch. Proc Natl Acad Sci U S A. 2006;103:3592-3597.

24. Shah VN, Chagot B, Chazin WJ. Calcium-dependent regulation of ion channels. Calcium Bind Proteins. 2006;1:203-212.

25. Zheng W, Hussein S, Yang J, Huang J, Zhang F, Hernandez-Anzaldo S, Fernandez-Patron C, Cao Y, Zeng H, Tang J, Chen XZ. A novel PKD2L1 C-terminal domain critical for trimerization and channel function. Sci Rep. 2015;5:9460.

26. Shen PS, Yang X, DeCaen PG, Liu X, Bulkley D, Clapham DE, Cao E. The structure of the polycystic kidney disease channel PKD2 in lipid nanodiscs. Cell. 2016;167:763-773.e11. 